\title{
LEITURA E ESCRITA COMO PRÁTICAS DE RESISTÊNCIA: CONSTRUINDO AGENCIAMENTOS NA ESCOLA
}

\section{READING AND WRITING AS RESISTANCE PRACTICES: BUILDING AGENCYING IN THE SCHOOL}

\author{
Atauan Soares de Queiroz ${ }^{1}$ \\ Instituto Federal da Bahia (IFBA) \\ Juliana de Freitas Dias ${ }^{2}$ \\ Universidade de Brasília (UnB)
}

\begin{abstract}
RESUMO
Este artigo propõe considerações reflexivas sobre discursos e práticas de (micro)resistência crítica e criativa relacionadas ao debate sobre gênero social no contexto escolar. Para delinear traços da conjuntura global, inicialmente, apresenta os pressupostos que sustentam os discursos conservadores no campo da educação, considerando suas conexões com processos históricos e socioculturais. Em seguida, aborda práticas de (micro)resistência no contexto do Ensino Médio que envolvem práticas de leitura crítica e produção de textos autorais marcados por discursos antissexistas, tomando como referência as experiências sociopedagógicas construídas no Projeto Mulheres Inspiradoras. Por fim, coloca em evidência as práticas de escrita autoral que concorrem para a reelaboração reflexiva e identitária e para a cidadania ativa. Em termos de microanálise, mobiliza categorias linguístico-discursivas do significado acional do discurso (FAIRCLOUGH, 2003), especificamente a intertextualidade e a pressuposição, que apontam para agenciamentos epistêmicos, políticos e identitários por parte dos/as estudantes.
\end{abstract}

PALAVRAS-CHAVE: Discurso; Práticas de escrita; Agenciamento.

\begin{abstract}
This paper proposes reflective considerations on discourses and practices of critical and creative (micro) resistance related to the debate on social gender in the school context. To outline features of the global conjuncture, initially, it presents the assumptions that support conservative discourses in the field of education, considering their connections with historical and socio-cultural processes. Then, it addresses practices of (micro) resistance in the context of high school that involve practices of critical reading and production of authorial texts marked by anti-sexist speeches, taking as a reference the socio-educational experiences built in the Inspiring Women Project. Finally, it highlights the practices of authorial writing that contribute to reflective and identity rework and active citizenship. In terms of microanalysis, it mobilizes linguistic-discursive categories of the actional meaning of discourse (FAIRCLOUGH, 2003), specifically intertextuality and presupposition, which point to epistemic, political, and identity agencying by students.
\end{abstract}

KEY WORDS: Discourse; Writing practices; Agencying.

\section{Discursos conservadores na educação: mapeando a conjuntura}

Neste trabalho, apresentamos um recorte do estudo de doutoramento intitulado "Educação crítica decolonial e agenciamentos: um estudo etnográfico-discursivo sobre o Programa Mulberes Inspiradoras"

\footnotetext{
${ }^{1}$ Doutor em Linguística pela Universidade de Brasília (UnB). Professor de Língua Portuguesa do Instituto Federal da Bahia (IFBA).E-mail: atauansoares@gmail.com

2 Doutora em Linguística pela Universidade de Brasília (UnB). Professora do Programa de Pós-graduação em Linguística da Universidade de Brasília (PPGL/UnB). E-mail: ju.freitas.d@gmail.com
} 
(QUEIROZ, 2020). Em termos de plano composicional, estruturamos o texto em três momentos. Primeiramente, para delinear traços da conjuntura global, trazemos os pressupostos que sustentam os discursos conservadores no campo da educação, considerando suas conexões com processos históricos e socioculturais. Em seguida, abordamos práticas de (micro)resistência no contexto do Ensino Médio (EM) que envolvem práticas de leitura crítica e produção de textos autorais marcados por discursos antissexistas, tomando como referência as experiências sociopedagógicas construídas no Projeto Mulheres Inspiradoras (PMI). Por fim, colocamos em evidência as práticas de escrita autoral que concorrem para a reelaboração reflexiva e identitária e para a cidadania ativa. Em termos de microanálise, mobilizamos categorias linguístico-discursivas do significado acional do discurso (FAIRCLOUGH, 2003), especificamente a intertextualidade e a pressuposição.

O debate sociopedagógico sobre gênero em perspectiva discursiva crítica e criativa, na escola, tem-se tornado cada vez mais pertinente e necessário porque os dias atuais estão marcados por uma forte onda de intolerância, nos âmbitos mais variados da existência humana. No Brasil e no mundo, estamos testemunhando um crescimento vertiginoso e organizado de campanhas antigênero e antifeminismo, lideradas por movimentos conservadores, religiosos e nacionalistas, que pregam um suposto retorno ao "bom senso" e a defesa dos valores da família tradicional (KUHAR; PATERNOTTE, 2017).

No campo da Educação, por exemplo, a bandeira da chamada Escola sem Partido ${ }^{3}$ (ESP) distorce tal debate de modo sistemático, com discursos conservadores, que naturalizam problemas de ordem social e normalizam práticas e comportamentos anticivilizatórios e excludentes. Ao defender os valores da família tradicional, observa-se que a agenda do ESP concebe gênero e sexualidade a partir de discursos moral-tradicionalistas, terapêuticos e religioso-radicais (FURLANI, 2011), os quais apresentam princípios em comum, sobretudo o controle e a regulação dos corpos e as formas de fechamento da democracia em relação a possibilidades outras de exercer a cidadania sexual.

Conhecido também como Lei da mordaşa, o movimento/projeto/programa ESP configurase como ativismo conservador que viola os princípios da educação democrática, os direitos humanos, a livre circulação de conhecimento nas diferentes disciplinas, favorecendo a agenda neoliberal de setores e grupos específicos da sociedade em detrimento dos interesses das mulheres, da população LGBT e, também, das classes materialmente desprivilegiadas, uma vez que fomenta apatia política e postura acrítica diante do atual estado das coisas.

Apesar de não ter se tornado lei nacional, o programa ESP tem gerado ressonâncias na conjuntura política educacional e em muitos espaços escolares pelo Brasil. Nas 600 (seiscentas) páginas da Base Nacional Comum Curricular (BNCC), por exemplo, considerando Ensino Fundamental (EF) e EM, a palavra gênero aparece 320 vezes. Em 319 ocorrências, é utilizada para se referir aos gêneros do discurso, figurando com outra acepção apenas uma vez, associada ao funcionamento das flexões vocabulares (número, gênero, tempo, pessoa etc.). Os itens lexicais "sexo" e "sexualidade" são mobilizados em três momentos, exclusivamente com sentido biológicohigienista (FURLANI, 2011). As expressões sexismo, misoginia, homofobia e LGBTfobia não são mencionadas em parte alguma, nem com formas similares. Assim, no tocante às questões de gênero, observa-se que a BNCC se configura como um dispositivo de parametrização do ensino que reforça a colonialidade e o (hetero)patriarcado. A tentativa de silenciar o debate é, sem dúvida, efeito político das mobilizações conservadoras (BIROLI, 2018). Embora o programa ESP se declare como "uma iniciativa conjunta de estudantes e pais preocupados com o grau de contaminação político-ideológica das escolas brasileiras em todos os níveis: do ensino básico ao superior ${ }^{4 \prime}$, a ofensiva conservadora se tornou mais aguda porque hoje ocupa acento no legislativo municipal, estadual e federal (BIROLI, 2018).

\footnotetext{
${ }^{3}$ Disponível em: https://www.programaescolasempartido.org/projeto.

${ }^{4}$ Disponível em: https://www.escolasempartido.org/quem-somos/. Acesso em 14 de abril de 2019.
} 
Indo de encontro à laicidade do Estado, ao indexicalizar pautas e discursos conservadores e até mesmo fascistas, atrelados a ideais políticos da extrema-direita, sobretudo de grupos integrantes da aliança conhecida como BBB (boi, bala e Bíblia) ${ }^{5}$, o ESP objetiva o controle do trabalho docente, desprofissionalizando-o e colocando professores/as e estudantes em relação de tensão nada produtiva em termos qualitativos, bem como o enfraquecimento das ações coletivas de movimentos sociais que buscam relações sociais mais justas e inclusivas, dentro e fora da escola. O ESP é, além de um programa de censura política e moral que propaga discursos essencialistas de gênero, um dispositivo de manipulação, que desvia a atenção da população dos problemas estruturais reais da educação brasileira para problemas inexistentes, uma vez que não há estudos que comprovem a presença da doutrinação marxista ou do marxismo culturat nas escolas.

Em tempos de fake news, em que a opinião pública é construída a partir de informações produzidas, compartilhadas, remixadas e consumidas sem critério, especialmente nas redes sociais digitais como Whatsapp, Facebook, Instagram e Twitter, expressar e defender opiniões/pautas mais progressistas na escola, como a equidade de gênero, é motivo para linchamento virtual e até mesmo físico. Vemos o processo de criminalização do exercício do magistério ganhar espaço, uma vez que docentes são tratados/as como terroristas ideológicos (MCLAREN, 2008) ao expressarem insatisfação em relação às decisões e às posturas antidemocráticas do governo, ao defenderem a laicidade do Estado e ao buscarem promover o debate sociopedagógico sobre gênero e sexualidade na escola, o qual tem sido reduzido pelo atual governo brasileiro a uma espécie de pauta "comunista". Com base nessa compreensão equivocada, as políticas identitárias tornam-se exclusivamente uma pauta político-partidária da agenda da oposição que, exatamente por isso, deve ser expurgada.

Conectadas ao ESP, vale destacar as críticas à chamada ideologia de gênero e ao kit gay. Como estratégia discursiva de manipulação da opinião pública, o ESP popularizou no Brasil o termo "ideologia de gênero", "rubrica sob a qual os atores conservadores vêm reunindo movimentos sociais, agendas e políticas públicas que estejam em sua mira", com o intuito de reverter "políticas para igualdade de gênero e para a superação de preconceitos e violências" (BIROLI, 2018, p. 163). Remetendo-se às origens da expressão, Garbagnoli (2014, p. 149) afirma que se trata "de uma invenção polêmica dos meios conservadores católicos que visa caricaturizar e, assim, deslegitimar um campo de estudos". Prova disso é que a estudiosa Judith Butler, quando veio ao Brasil ministrar seminário dedicado ao tema Os fins da democracia, no ano de 2017, sofreu diferentes ataques por sua teoria de gênero. As pessoas que se opuseram à presença dela no país viam-na equivocadamente como uma proponente da "ideologia de gênero", por "não acreditar" em restrições sexuais e por ter elaborado uma teoria que "destrói" ensinamentos bíblicos. Sobre o acontecimento, a autora questiona:

Por que um movimento a favor da dignidade e dos direitos sexuais e contra a violência e a exploração sexual é acusado de defender pedofilia se, nos últimos anos, é a Igreja Católica que vem sendo exposta como abrigo de pedófilos, protegendo-os contra processos e sanções, ao mesmo tempo em que não protege suas centenas de vítimas? Será possível que a chamada ideologia de gênero tenha virado um espectro simbólico de caos e predação sexual precisamente para desviar as atenções da exploração sexual e corrupção moral no interior da Igreja Católica, uma situação que abalou profundamente sua autoridade moral? Será que precisamos compreender como funciona "projeção" para compreendermos como

\footnotetext{
${ }^{5}$ A ala conservadora é composta por três bancadas - Boi (bancada ruralista), Bala (bancada com interesse na indústria armamentista e empresas de segurança) e Bíblia (bancada evangélica) -, mas "a aliança Bíblia-bala tem mais sustentação ideológica", uma vez que adota e reforça "o discurso de que algumas formas desejáveis de ordem social estão sendo ameaçadas" (BIROLI, 2018, p. 164).

${ }^{6}$ Tais expressões têm sido utilizadas frequentemente por políticos liberais da (extrema) direita para justificar o projeto ESP.
} 
uma teoria de gênero pôde ser transformada em "ideologia diabólica?" (BUTLER, 2017).

As indagações da autora revelam como o discurso da "ideologia de gênero" manipula a opinião pública, por meio da dissimulação e do expurgo do outro (THOMPSON, 1990), distorcendo as finalidades da teoria e colocando acusado (Igreja Católica) em papel de vítima. A falta de conscientização política cria terreno para "fanatismos destrutivos" (FREIRE, 2012, p. 28): no dia do seminário, pessoas queimaram uma efígie de Butler como se fosse uma bruxa, assim como ocorreu com inúmeras mulheres queimadas vivas em espaços públicos, na Idade Média e no período da colonização das Américas, cujas crenças não se filiavam aos dogmas da Igreja Católica (FEDERICI, 2017). O ativismo teórico da autora, em verdade, busca defender a democracia de modo que os direitos sexuais sejam garantidos e a violência contra minorias sexuais e de gênero seja execrada. Para ela, o gesto simbólico de queimar a imagem transmitiu uma mensagem aterrorizante e ameaçadora para todas as pessoas que acreditam na igualdade das mulheres e no direito de mulheres e LGBT serem protegidos/as contra violência e assassinato (BUTLER, 2017).

Filiado a formações discursivas heteropatriarcais, capitalistas e coloniais, o discurso da "ideologia de gênero" distorce as narrativas contra-hegemônicas dos processos históricos e políticos e promove um desserviço social em termos de inclusão ao atacar a cidadania sexual. Para Kuhar e Paternotte (2017, p. 9), a "ideologia de gênero" é "destrutiva, obscurantista, antissocial, antipopular" e apresenta uma tripla dimensão: é, ao mesmo tempo, discurso, estratégia e fenômeno social. A mobilização contra a suposta "ideologia de gênero" tem ocorrido em vários países europeus (Alemanha, Áustria, Bélgica, Croácia, Eslovênia, Espanha, França, Hungria, Irlanda, Itália, Polônia e Rússia) e se propagado para países de outros continentes, como o Brasil (KUHAR; PATERNOTTE, 2017). Ainda que cada país tenha especificidades nas mobilizações contra relações de gênero mais inclusivas, com diferentes formas de atuação, algumas mais brandas, outras mais ostensivas, todos elas têm um grupo alvo preferencial: ativistas, feministas e comunidade LGBT. Segundo os autores, as campanhas antigênero, lideradas por atores religiosos conservadores e inspiradas no pensamento de ideólogos neoliberais, atacam sobretudo a educação sexual e de gênero, os estudos de gênero e a democracia, os direitos reprodutivos e os direitos da população LGBT.

Constata-se, assim, que não há igualdade nos espaços sociais e a agenda de LGBT e mulheres se torna um problema político. Embora o alvo sejam grupos sociais específicos, "o embate é com uma sociedade em transformação" (BIROLI, 2018, p. 205). A campanha conservadora propagada pelo ESP atua de várias maneiras, voltando-se também para o controle da circulação e do consumo de materiais pedagógicos. O kit gay, por exemplo, é uma expressão preconizada por grupos políticos LGBTfóbicos e fundamentalistas religiosos para se referirem ao kit educativo anti-homofobia, um material pedagógico integrante do Projeto Escola sem Homofobia (PESH), composto de um caderno, seis boletins, três produtos audiovisuais com suas respectivas orientações, um cartaz e uma carta de apresentação para gestores/as e educadores/as (MELLO et al, 2012).

O material, financiado pelo Ministério da Educação (MEC), foi produzido em parceria com ONGs e com apoio da Associação Brasileira de Gays, Lésbicas, Bissexuais, Travestis e Transexuais (ABGLT) e da Global Aliance for LGBT Education (GALE). Os atores conservadores se opuseram à distribuição do referido material, com o argumento de que faria apologia à homossexualidade entre jovens e estimularia a pedofilia (MELLO et al, 2012). Embora várias organizações tenham se manifestado favoravelmente à proposta pedagógica do $\mathrm{PESH}$, tendo em vista a relevância do enfrentamento da LGBTfobia no espaço escolar e a adequação do material proposto às faixas etárias e ao desenvolvimento afetivo-cognitivo a que se destina, a distribuição do kit educativo anti-homofobia foi suspensa (MELLO et al, 2012). Nenhuma escola recebeu 
exemplares do material. Apesar de o fato ter ocorrido em 2011, até hoje é referenciado pelos mesmos políticos conservadores de modo distorcido.

Em suma, em países que realizam campanha antigênero e antifeminismo, há a crescente circulação de discursos orientados por uma nova dinâmica epistemológica em que a tônica são as epistemologias da ignorância, isto é, epistemologias que servem para marginalizar e distorcer determinados tipos de conhecimento, especialmente os contra-hegemônicos, e obliterar ou silenciar o que sempre existiu e esteve disponível (SULLIVAN; TUANA, 2007; MALEWSKI; JARAMILLO, 2011). Há um movimento geopolítico na atualidade de propagação de práticas e ideais retrógrados e conservadores praticado por grupos políticos da (extrema) direita ou da direita alternativa (alt-right), com uma agenda anti-intelectual cultivada culturalmente que invade as escolas.

O negacionismo, por exemplo, é uma das mais evidentes expressões das epistemologias da ignorância. Originado em contexto europeu, o conceito de negacionismo vincula-se estritamente à reação de certos grupos da sociedade no período pós-guerra, em relação ao genocídio perpetrado pelos nazistas, particularmente do holocausto judeu. O conceito surgiu com o historiador francês Paul Rassiner, que propôs a tese de que nunca ocorreu uma aniquilação sistemática da população judia e que o número de vítimas foi menor do que os dados oficiais atestam (MEZALOPEHANDÍA, 2018). Em suma, o negacionismo falseia os acontecimentos históricos, constituindo-se em uma oposição à historiografia científica.

O termo surge em solo europeu para tratar especificamente do holocausto judeu e se propaga pelos demais continentes desvirtuando, negando ou minimizando outros tipos de crime contra a humanidade e, também, em relação a fatos históricos comprovados cientificamente. No Brasil, por exemplo, esse revisionismo histórico tem sido utilizado como uma arma política para legitimar os interesses de políticos e grupos da (extrema) direita que, com frequência, negam a ditadura militar ocorrida em 1964 e afirmam que o nazismo é um movimento de partidos políticos da esquerda (NEHER, 2019). Para legitimar seus projetos políticos, adeptos do negacionismo têm manipulado fatos e tornado inimigo público todos/as aqueles/as que representam uma ameaça às suas ideologias.

O negacionismo gera impactos negativos imensuráveis no contexto escolar, uma vez que estimula a postura acrítica diante dos acontecimentos históricos e das práticas acadêmico-científicas de produção do conhecimento. Contrariando sobretudo consensos na esfera acadêmica, o negacionismo rejeita, dentre outras coisas, evidências científicas (aquecimento global) e evidências documentais (ditadura militar e regime escravista), e defende ideias controversas, como o terraplanismo, o criacionismo e o movimento antivacina. Também está vinculado à negação e ao reforço dos diferentes tipos de opressão: mulheres, negros/as, indígenas, LGBT seriam vitimistas e suas denúncias, ilegítimas; no Brasil, não há racismo (mito da democracia racial).

A perseguição a professores/as, pesquisadores/as e estudantes e o cerceamento da liberdade das universidades e das escolas legitima as epistemologias da ignorância, ocorrendo de modo preocupante no mundo e no Brasil. De acordo com o relatório Free to think, de 2019, no Brasil, as pressões sobre comunidades universitárias dispararam nas eleições presidenciais do país em outubro de 2018 e se intensificaram desde a assunção do presidente Jair Messias Bolsonaro. Invasões policiais em universidades públicas brasileiras, ameaças a estudantes e estudiosos minoritários, ações orçamentárias e legislativas que minam as instituições de ensino superior e limitam a liberdade acadêmica e a autonomia institucional, constituem o espelho das estratégias encontradas em diferentes nações onde o conceito de "democracia liberal" ganhou força entre líderes políticos (FREE TO THINK, 2019).

Esses discursos e essas práticas anticivilizatórios e fascistas, baseados em epistemologias da ignorância e preconizados por grupos políticos da extrema direita ou da direita alternativa (alt-right) por várias vias, principalmente pelas mídias sociais digitais, com a atuação das milícias digitais (ROCHA, 2020), filiam-se a formações discursivas conservadoras conectadas a um movimento geopolítico que opera em escala global, com diferentes ressonâncias em nível local. As formações 
discursivas conservadoras, por sua vez, filiam-se a uma formação ideológica capitalista orientada pela lógica da exclusão e do expurgo do outro.

Para intelectuais da extrema direita e, consequentemente, para as milícias digitais, o verbo dominante é "eliminar" e o substantivo é "limpeza" (ROCHA, 2020). Atores sociais conservadores tornam-se, assim, "máquinas desejantes de necropoder e partidárias do eliminar e destruir os 'outros', contrárias ao que torna o ser humano um curador poliético do mundo da vida em sua totalidade" (GALEFFI, 2020, p. 7). Quando grupos populacionais como professores/as, estudantes, mulheres, LGBT, indígenas, negros/as, são alvo de perseguição e se tornam inimigos políticos por lutarem pela preservação de direitos conquistados, não há exagero algum ao pensar em um nazicapitalismo mundial integrado (GALEFFI, 2020), um capitalismo fascista, racista, (hetero)patriarcal e colonial recrudescido por políticas cada vez mais neoliberais que distorcem, enfraquecem e/ou eliminam toda e qualquer pauta progressista, e diluem os laços de solidariedade, tornando a vida mais precária (BUTLER, 1993; BIROLI, 2018). Esse movimento conservador gera ressonâncias em diferentes espaços sociais, organizações e instituições como, por exemplo, a escola.

\section{Projeto Mulheres Inspiradora: ação coletiva de resistência}

Apesar de esses discursos conservadores constrangerem o pensamento das sociedades contemporâneas, interferindo, consequentemente, no fortalecimento de grupos sociais minoritários, o enfrentamento às diferentes formas de opressão no que diz respeito à identidade de gênero e às relações de gênero tem adquirido força nas duas últimas décadas, no Brasil e no mundo, sobretudo porque corpos de mulheres e população LGBT passaram a existir politicamente, o que possibilitou a visibilização de compreensões e experiências sociais outras, não hegemônicas, acerca das políticas de gênero na relação com outras inscrições identitárias. De acordo com Archer (2004, p. 279), classe, sexo e etnia constituíram a "tríade de novos agentes engajados em todo o mundo". Defendendo seus interesses e suas necessidades, esses/as agentes engajados têm promovido avanços institucionais que motivaram "a incorporação social de direitos civis, cidadania, previdência social, educação, serviços de saúde” (ARCHER, 2004, p. 279).

Neste trabalho ${ }^{7}$, focalizamos uma ação coletiva de resistência construída no chão da escola pública, o Projeto Mulheres Inspiradoras 8 (PMI). O PMI foi criado pela professora Gina Vieira Ponte de Albuquerque, no ano de 2014. Em 2017, depois de receber inúmeras premiações, tornouse programa da rede pública de educação do Distrito Federal (DF). Oito ações estruturam as práticas sociopedagógicas do Programa de Ampliação da Área de Abrangência do Projeto Mulheres Inspiradoras (PAPMI), quais sejam:

Quadro 1 - Ações do Projeto Mulheres Inspiradoras

\begin{tabular}{ll}
\hline \multicolumn{1}{c}{ Ações } \\
\hline 1 & Leitura de seis obras de autoria feminina: O Diário de Anne Frank, de Annelies Marie Frank; Eu \\
& sou Malala, de Malala Yousafzai; Quarto de Despejo: diário de uma favelada, de Carolina Maria de Jesus, \\
& Não vou mais lavar os pratos, Só por hoje vou deixar o meu cabelo em paz, Espelho, Miradouros, Dialéticas da \\
& Percepsão (os três últimos da autoria de Cristiane Sobral); \\
\hline 2 & Estudo da biografia de 10 mulheres inspiradoras: Anne Frank, Carolina Maria de Jesus, Cora \\
& Coralina, Irena Sendler, Lygia Fagundes Telles, Malala Yousafzai, Maria da Penha, Nise da \\
& Silveira, Rosa Parks e Zilda Arns; \\
\hline
\end{tabular}

\footnotetext{
7 A investigação foi autorizada pela Universidade de Brasília (UnB) e aprovada pelo Comitê de Ética em Pesquisa (CEP), por meio da Plataforma Brasil, conforme parecer consubstanciado n. 3.070.769, estando de acordo com as Resoluções Éticas Brasileiras, em especial as resoluções do Conselho Nacional de Saúde (CNS) 466/2012 e 510/2016. ${ }^{8}$ Para acessar informações pormenorizadas sobre o PMI, sugiro a leitura do dossiê Projeto Mulheres Inspiradoras, que se encontra disponível em: https://periodicos.unb.br/index.php/les/issue/view/1123.
} 


\begin{tabular}{ll}
\hline 3 & Entrevista com mulheres de destaque na comunidade; \\
\hline 4 & $\begin{array}{l}\text { Campanha de combate à violência contra a mulher: "Nós dizemos não a qualquer forma de } \\
\text { violência contra a mulher"; }\end{array}$ \\
\hline 5 & $\begin{array}{l}\text { Realização de entrevista, pelos/as estudantes, com uma mulher do próprio círculo social, que eles } \\
\text { considerassem inspiradora; }\end{array}$ \\
\hline 6 & $\begin{array}{l}\text { Transformação da entrevista em um texto autoral de natureza biográfica, no qual narrassem a } \\
\text { história de vida da mulher inspiradora eleita por eles/as; }\end{array}$ \\
\hline 7 & $\begin{array}{l}\text { Estudo de casos, debate, trabalho em grupo, mesa-redonda e mostra de vídeo sobre o uso } \\
\text { consciente e seguro das redes sociais digitais, sobretudo, no que diz respeito ao sexting, ao } \\
\text { ciberbullying e à ciberviolência contra a mulher; }\end{array}$ \\
\hline 8 & Lançamento de livro com as biografias de mulheres escritas pelos/as estudantes. \\
\hline
\end{tabular}

Essas ações, propostas pela professora Gina, foram adaptadas e ressignificadas pelas docentes participantes do PAPMI. Os dados empíricos que compõem este trabalho foram gerados em pesquisa ${ }^{9}$ de abordagem etnográfico-discursiva em uma escola participante do PAPMI. Os/as agentes colaboradores/as do estudo foram estudantes de duas turmas do EM (uma turma do segundo ano e uma do terceiro). Para operacionalizar a investigação, utilizamos abordagem multimetodológica constituída de textos autorais produzidos pelos/as estudantes (diário de bordo), observações de aula, notas de campo e rodas de conversa. Acompanhamos a realização de atividades pedagógicas desenvolvidas pelas docentes colaboradoras no período de maio a dezembro de 2017. Na escola observada, identificamos três tipos de práticas discursivo-identitárias, isto é, práticas que envolvem a produção, circulação e consumo de textos relacionados ao debate sobre gênero e outras inscrições identitárias, durante a aplicação do PMI, conforme descrição a seguir:

Quadro 2 - Rede de práticas discursivo-identitárias do PMI

Tipos Práticas

\begin{tabular}{|c|c|}
\hline $\begin{array}{l}\text { Tipo 1: Práticas discursivo- } \\
\text { identitárias ocorridas no espaço } \\
\text { da sala de aula e explicitamente } \\
\text { vinculadas ao PMI. }\end{array}$ & $\begin{array}{l}\text { Práticas de leitura, análise e interpretação das obras do PMI; } \\
\text { Práticas de escrita (gêneros discursivos: diário de bordo, entrevista, } \\
\text { biografia, poesias, cartazes multimodais); } \\
\text { Práticas de oralidade (gêneros discursivos: rodas de conversa, } \\
\text { seminário). }\end{array}$ \\
\hline $\begin{array}{l}\text { Tipo 2: Práticas discursivo- } \\
\text { identitárias ocorridas em outros } \\
\text { espaços da escola (auditório, } \\
\text { sala de vídeo, quadra } \\
\text { poliesportiva) e explicitamente } \\
\text { vinculadas ao PMI. }\end{array}$ & $\begin{array}{l}\text { Mesa-redonda Meninas: mulheres inspiradoras; } \\
\text { Mesa-redonda Você não está só: juntos formaremos um arco-íris; } \\
\text { Roda de conversa com a escritora Cristiane Sobral; } \\
\text { Palestra com a professora Gina Vieira Ponte de Albuquerque; } \\
\text { Palestra Direitos Humanos para redação no ENEM; } \\
\text { Cineclube Mulheres Inspiradoras; } \\
\text { Projeto Pedal Social. }\end{array}$ \\
\hline $\begin{array}{l}\text { Tipo 3: Práticas discursivo- } \\
\text { identitárias ocorridas no espaço } \\
\text { da sala de aula e não vinculadas } \\
\text { explicitamente ao PMI, mas que } \\
\text { tematizam a valorização da }\end{array}$ & $\begin{array}{l}\text { Práticas de leitura, análise e interpretação de textos de gêneros diversos } \\
\text { e de obras literárias exigidos pelo PAS; } \\
\text { Práticas de escrita (gêneros discursivos: dissertação argumentativa, } \\
\text { atividades e avaliações escritas); } \\
\text { Práticas de oralidade (gênero discursivo: seminário). }\end{array}$ \\
\hline
\end{tabular}
Fonte: elaboração própria.

\footnotetext{
${ }^{9}$ A investigação etnográfico-discursiva em tela foi autorizada pela UnB e aprovada pelo Comitê de Ética em Pesquisa (CEP), por meio da Plataforma Brasil, conforme parecer consubstanciado n. 3.070.769, estando de acordo com as Resoluções Éticas Brasileiras, em especial as resoluções do Conselho Nacional de Saúde (CNS) 466/2012 e 510/2016.
} 
Dentre as inúmeras ações desenvolvidas no âmbito do PMI, destacamos neste trabalho as práticas de leitura envolvendo a obra literária Não vou mais lavar os pratos e as práticas de produção escrita autoral (cartazes multimodais ${ }^{10}$ e produção literária). A referida obra literária é da autoria de Cristiane Sobral, escritora negra carioca, residente e domiciliada em Brasília desde o início da década de 90. A obra reúne 92 poemas com diferentes temas: memórias, juventude, feminismo, ancestralidade, maternidade. As poesias, em sua maioria com versos livres, caracterizam-se pelo engajamento político e denunciam os sistemas de opressão relativos a gênero, à classe e à raça. Com frequência, o eu lírico critica o patriarcado, o padrão eurocêntrico de beleza e as funções sociais das mulheres, em especial da mulher negra, e sugere transformação pelo empoderamento, pela conscientização crítica e por diferentes práticas de resistência, principalmente pela autoaceitação. A obra foi lida, comentada e debatida ao longo de duas semanas (21/08 a 30/08/2017. Além das rodas de leitura e de conversa, os/as estudantes também produziram textos.

Para perceber como as práticas de escrita autoral se configuram como práticas de resistência, as análises linguístico-discursivas dos dados foram fundamentadas na Análise de Discurso Crítica (CHOULIARAKI; FAIRCLOUGH, 1999; FAIRCLOUGH 2016 [1992], 2003), que tem potencial para produzir análises que buscam "descrever as categorias que são generativas na produção discursiva e é capaz de leituras de textos que vão para lá dos significados superficialmente acessíveis, fornecendo, assim, outros meios de acesso à organização sociocultural" (PEDRO, 1997, p. 25).

No tocante à microanálise, interessa-nos o significado acional do discurso, que, segundo Fairclough (2003), diz respeito aos modos relativamente estáveis de (inter)agir com e sobre os outros. Relacionado aos gêneros discursivos, as categorias analíticas do significado acional mostram como textos impactam as relações sociais, as identidades e os agenciamentos. Compreendemos que agenciamento é um processo sociodiscursivo de reelaboração (meta)reflexiva e produção de si, na perspectiva da agência engajada, que se relaciona com processos de conscientização identitária, constrangidos inevitavelmente pelos efeitos causais das interações entre estruturas sociais e econômicas e sistemas culturais. Os agenciamentos ocorrem de modos diferentes e singulares, pois dependem da maneira como a identidade pessoal do ator e da atriz social é afetada pelas experiências em práticas sociais e práticas discursivas (ARCHER, 2004). É uma questão de abertura também. Nas análises constantes no trabalho, mobilizamos duas categorias do significado acional, a intertextualidade e a pressuposição, para observar como os processos sociodiscursivos de agenciamentos ocorrem.

A intertextualidade é um elemento estruturante e uma prática fundamental para a compreensão, interpretação e produção de textos em quaisquer esferas discursivas. Desdobrando a noção de intertextualidade para as práticas de produção escrita no contexto educacional, Curi (1998) propõe que reprodução, paráfrase reprodutiva, paráfrase criativa e criação, são as formas convencionais mais utilizadas. A criação estaria, nessa lógica, associada à formação do sujeito-autor, ou seja, a posicionamentos discursivos mais agentivos (QUEIROZ, 2015). Apesar de o autor propor sua teorização restringindo-se à produção escrita, considero que essas práticas intertextuais também se aplicam à oralidade.

Em perspectiva crítica, a intertextualidade é, além de propriedade textual e de prática, um elemento linguístico-discursivo, que itera e propaga discursos e ideologias. Segundo Ramalho e Resende (2011), intertextualidade diz respeito à presença e/ou ausência de vozes, que, articuladas de maneira específica, sinalizam o posicionamento do texto em lutas hegemônicas. Essa articulação de vozes em textos pode ser disciplinadora ou transformadora em relação às lutas de poder.

\footnotetext{
${ }^{10}$ A multimodalidade diz respeito à coocorrência de diferentes semioses em textos (KRESS; VAN LEEUWEN, 1996). Como nosso interesse neste trabalho se volta para agenciamentos sociodiscursivos envolvendo práticas intertextuais e pressuposição, não abordaremos especificidades do texto multimodal.
} 
Ao abordar as características da intertextualidade, Fairclough 2003 sublinha que se trata de um mecanismo linguístico inevitavelmente seletivo em relação às informações incluídas e excluídas dos eventos e textos. A realização da intertextualidade pode se dar de modo implícito e explícito. Em relação às práticas intertextuais implícitas, Fairclough (2003, p. 55) chama atenção para o potencial ideológico da pressuposição, que é uma "propriedade difusa dos textos e uma propriedade de considerável importância social".

Como mecanismo linguístico, as pressuposições moldam, por exemplo, formas de identificação de gênero. Segundo Fairclough (2016[1992]), as pressuposições podem ser utilizadas como recurso efetivos de manipulação, uma vez que um texto pode indexicalizar uma proposição estabelecida desonestamente. Por serem difíceis de contestar, requerem "sujeitos interpretantes com experiências e suposições particulares em textos anteriores" (FAIRCLOUGH, 2016[1992], p. 163). É importante destacar que as categorias selecionadas são aplicadas nas análises em conformidade com o tipo de dado etnográfico em foco. Não são as categorias que estruturam as análises, mas os dados empíricos que vão exigindo a mobilização das categorias específicas.

\section{Práticas de escrita: produzindo (micro)resistências na escola}

O cartaz multimodal a seguir, produzido pelos/as estudantes, aciona discursos de contestação às ideologias indexicalizadas nos discursos hegemônicos, que regulam o corpo feminino, materializando semioticamente formas de resistência no contexto escolar:

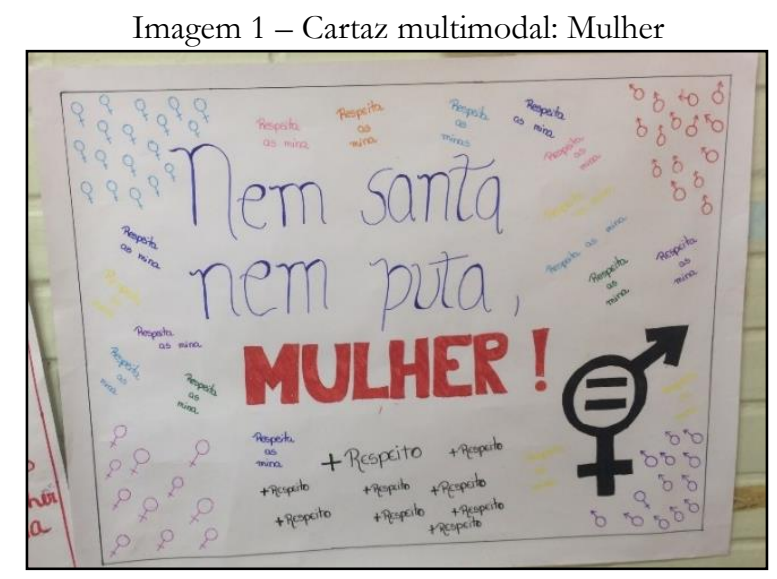

Fonte: produção dos/as estudantes.

Nessa produção multimodal, a prática de resistência consiste na contestação das ordens de gênero por meio da desconstrução de ideologias que naturalizam o comportamento feminino a partir de oposições binárias cristalizadas pela cultura: a mulher que itera discursos, práticas, crenças, valores de uma sociedade (hetero)patriarcal e conservadora é representada como "santa". A mulher que rompe com esse padrão regulatório é, inevitavelmente, "puta". Nota-se, a partir desses enunciados, que as estruturas dominantes estabilizam e naturalizam as convenções sociais, ou seja, os efeitos do poder e da ideologia na produção de significados são obscurecidos e adquirem formas estáveis e naturais (FAIRCLOUGH, 2003). O cartaz propõe um discurso agenciador, em diálogo intertextual criativo com a obra Não vou mais lavar os pratos, que desestabiliza esse processo de naturalização potencialmente ideológico sobre as representações compartilhadas culturalmente acerca do corpo feminino. Os operadores "nem” rechaçam a regulação sobre o corpo para mostrar, ao final, que ser "mulher" é uma construção social, um substantivo elaborado pela própria atriz social, digna de respeito e reconhecimento, não um adjetivo atribuído pelas pessoas. A resistência é, então, construída como a ruptura das convenções e das práticas discursivas estáveis. 
Toda prática discursiva associa-se a processos identitários e gera impactos no eu, de diferentes modos. Quando consideramos os propósitos do PMI, podemos constatar que há práticas discursivas direcionadas para dimensões identitárias específicas dos atores e das atrizes sociais, com potencial para promover movimentos reflexivos, como na produção multimodal a seguir:

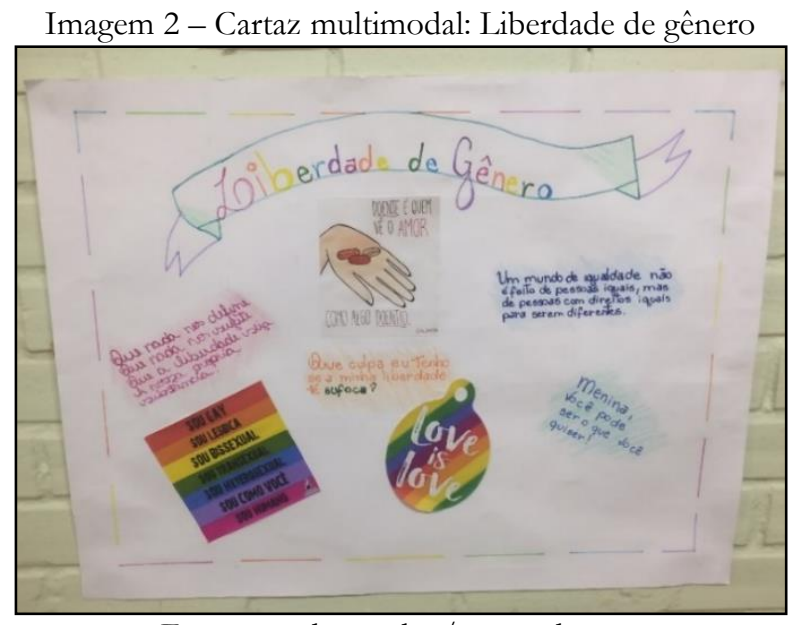

Fonte: produção dos/as estudantes.

A produção do cartaz materializa apenas uma atividade dentre tantas outras desenvolvidas pelas docentes, todavia, através dele, pode-se perceber que o PMI, enquanto projeto educacional crítico e decolonial, favorece a circulação de discursos não hegemônicos no espaço da escola que vão além do discurso da tolerância, que preconiza o "respeito" pela mulher e pelo diferente. $\mathrm{O}$ diálogo intertextual com a obra Não vou mais lavar os pratos se amplia, abordando a diversidade sexual. Trata-se do discurso da liberdade e da responsabilização pelo bem estar do outro através da aceitação da diferença e da diversidade como um ato de amor (HOOKS, 2013), reconhecendo a existência de outros corpos e outras identidades, como "gay, lésbica, bissexual, transexual". É o discurso da "responsabilidade de criar novas configurações de poder e conhecimento" (KILOMBA, 2019, p. 11). Não é a aceitação como conveniência ou como escolha, mas como espaço para a liberdade de ser do outro, afinal "doente é quem vê o amor como algo doentio". No cartaz, a mão aberta estendida com comprimidos, em posição central e superior, sugere que pessoas que veem o amor como algo doentio precisam de acompanhamento médico, subvertendo o discurso terapêutico de que práticas sexuais e afetivas não heteronormativas são "anormais" e que pessoas que vivenciam essas práticas precisam de cura (FURLANI, 2011). Deliberações reflexivas provocadas pela produção, circulação e consumo de textos com potencial agenciador concorrem para a construção de identidades de gênero cidadãs e plurais.

Segundo a professora Clarice ${ }^{11}$, agente colaboradora do estudo, ao ler criticamente a poesia de Cristiane Sobral, a literatura pode deixar de ser apenas um referencial teórico para tornar-se caminho de transformação social, uma vez que a poeta revela nossas angústias, inquietações, sentimentos, e nos mobiliza para a ação, com o/a estudante sentindo-se valorizado/a e respeitado/a e se enxergando nas produções literárias. A poética transgressiva de Cristiane Sobral também estimulou a produção de textos poéticos por parte dos/as estudantes. Inspirada na obra da autora, a estudante Vanessa produziu o texto poético Valsa das bastardas, analisado discursivamente na próxima seção.

${ }^{11}$ Para preservar a identidade das agentes colaboradoras, utilizamos nome fictício. 


\title{
3.1 "Eu não sou produto do teu mando"
}

\author{
Valsa das Bastardas
}

Eu não sou produto do teu mando.

Não sou escrava do teu desejo.

Não nasci pra te satisfazer.

Se queres algo, levanta e faça.

Rainha do lar, não empregada da tua preguiça.

Mãe de família, não robô sem descanso.

Namorada, não depósito da tua prepotência.

Amiga, não algo pra você tatear ou abusar quando quiser

Uma mulher qualquer na rua, não alvo da tua estupidez.

Eu tenho 18 anos, trabalho, estudo e gosto de sair

no final de semana e sou chamada de vagabunda por isso.

Eu tenho 34 anos. Meu marido me batia.

Larguei a casa para viver minha vida longe da violência.

Sou chamada de louca por isso.

Eu tenho 12 anos e meu corpo está em desenvolvimento

e já me cobram comportamento de "mocinha".

Senta direito.

Prende esse cabelo.

Tira esse batom.

Coloca outra roupa.

Tira esse perfume de mulher fácil.

Passa menos maquiagem.

Pinta esses brancos.

Faz essa sobrancelha.

Corta tuas asas, esconde tua coragem e rasga tua liberdade.

Te submete por obrigação. Cozinha logo esse arroz.

Está horrivel, sua mãe não te ensinou a cozinhar?

Preguicosa! Vai arrumar essa casa. Isso é coisa de mulher.

Futebol? Você é louca. Futebol é coisa de homem.

Tira essa camisa, desliga esse jogo, olha a louça pra lavar.

O que é impedimento? Me diz nome de dois ídolos desse clube?

Para de torcer.

Papai, en não sou mais princesa. Maturidade e dignidade.

A vida me escolheu pra ser guerreira.

Pra bater de frente, pra fazer diferente.

Pra repreender o inaceitável e ensinar o que se deve.

Pra não abaixar a cabeça pra injustiça, pra não calar minha voz. quando eu precisar falar. Pra que meus olhos contemplem as vitórias e aprenda com as derrotas.

Mamãe, a tua escola de guerreira funcionou. Tua coroa você honrou.

Por 18 anos o calvário carregou. E hoje aqui estou.

Carrego tua luta no peito, tua história em meu ser.

Obrigada por ser espelho, daquilo que eu sempre quis ser.

A produção poética de Vanessa se destaca pelo engajamento, pela potência crítica e pelo movimento autoral e agentivo ao recriar e sintetizar a obra Não vou mais lavar os pratos: leitura que se faz escritura e escritura que se faz leitura, impulsionando, inquietando-se, confundindo-se uma com a outra (LARROSA, 2004). A voz que enuncia no texto dialoga com uma segunda pessoa, do sexo masculino, cujo comportamento machista e cuja atitude iteram características das masculinidades hegemônicas e simplificadas, que costumam avaliar a mulher arbitrariamente como "submissa", "serva", "escrava", "robô". A voz agentiva de Vanessa compromete-se com a denúncia e aponta possibilidades de transformação social, sobretudo ao questionar as posições ocupadas pelas 
mulheres em diferentes espaços institucionais e sociais. A conscientização crítica acerca do pensar, do sentir e do agir parte do reconhecimento dos efeitos dos sistemas de opressão e das crenças, dos valores e hábitos que normatizam o corpo feminino e impõem modos particulares de agir, representar e identificar.

Vanessa simula vozes de outras mulheres, de diferentes gerações, histórias, classes, para questionar e combater discursos sexistas: a jovem de 18 anos que é julgada como "vagabunda" por gostar de sair aos fins de semana; a mulher de 34 anos que sofria violência doméstica e fugiu de casa; a adolescente de 12 anos que é cobrada a ter comportamento de "mocinha". As vozes-mulheres são mobilizadas por Vanessa para problematizar as normatizações sociais que são efeitos socioculturais das estruturas patriarcais e coloniais, apontando formas de resistência e reexistência e reinventando as relações de gênero: o bem viver requer igualdade de direitos e relações harmoniosas nos diferentes espaços e tempos sociais (HUANACUNI, 2010; WALSH, 2013).

A sequência de enunciados com verbos no modo imperativo mostra o quão asfixiantes e inegociáveis são (i) a regulação sobre o corpo feminino: senta direito, prende esse cabelo, tira esse batom, coloca outra roupa, tira esse perfume de mulher fácil, passa menos maquiagem, pinta esses brancos, faz essa sobrancelha; e (ii) a divisão social das tarefas domésticas, atribuídas exclusiva e culturalmente à mulheres: cozinha logo esse arroz, vai arrumar a casa, olha a louça pra lavar, para de torcer. O corpo é representado, assim, como território de disputa, que, quando sistematicamente controlado no próprio espaço do lar, fratura os processos metarreflexivos e fragiliza as possibilidades de agenciamento.

A poesia é repleta de metáforas que aparecem frequentemente no discurso do senso comum, objetificam o corpo da mulher, como "produto, escrava, empregada, robô, depósito, princesa", e impõem modos de ser e agir em conformidade com discursos conservadores a respeito do que se espera da mulher. Metaforicamente, Vanessa sintetiza o resultado do acúmulo de interdições: "corta tuas asas, esconde tua coragem e rasga tua liberdade", impeditivos para a experiência de vida com mais plenitude. Com base em Brown e Gilman, Fairclough (2003) sublinha que as relações sociais são construídas a partir de hierarquias sociais que variam entre a dimensão do poder e a dimensão da solidariedade. Transformar as relações de poder em relações solidárias é uma tarefa difícil e dolorosa, mas Vanessa, materializando semioticamente sua agência engajada, instaura essa possibilidade em sala de aula, por meio de um texto protagonista (MAGALHÃES, 2017), ao compartilhar dores, como marca dos seus agenciamentos, como maneira de incentivar as colegas do sexo feminino a se politizarem e como meio para fazer os colegas do sexo masculino a reconhecerem seus privilégios, que sobrecarregam o corpo feminino. "É por causa dos atos mobilizadores dos agentes sociais que a linguagem e os textos são protagonistas" (MAGALHÃES, 2017, p. 594)

A reiteração constante do advérbio não - primeira palavra do título da obra literária em estudo - revela a mulher que saiu da esfera do desejo pela liberdade e passou para o plano da realidade, representando-se como livre, forte e empoderada. "Em muitos casos de pressuposição, o 'outro texto' não é outro texto especificado ou identificável, mas um 'texto' mais nebuloso correspondendo à opinião geral” (FAIRCLOUGH, 2016[1992], p. 162). A opinião geral pressuposta na poesia é aquele texto nebuloso que impõe regulações arbitrárias sobre corpo feminino, em suas diferentes dimensões (física, intelectual, emocional, ética). Vanessa utiliza a negação como modo de se autoafirmar e de definir uma ruptura na linha temporal (eu era, não sou mais).

Segundo Fairclough (2003, p. 163), enunciados negativos "carregam tipos especiais de pressuposição que também funcionam intertextualmente, incorporando outros textos somente para contestá-los ou rejeitá-los". Nesse sentido, a repetição do advérbio de negação “não" funciona como estrutura linguística para a pressuposição, em que a estudante rechaça imposições socioculturais e simbólicas e assume nova posição, uma nova identificação, com força agentiva e 
engajada, que desnarrativiza discursos opressores cristalizados sobre o corpo feminino e revela agenciamento identitário e político:

Figura 1 - Identificações outras

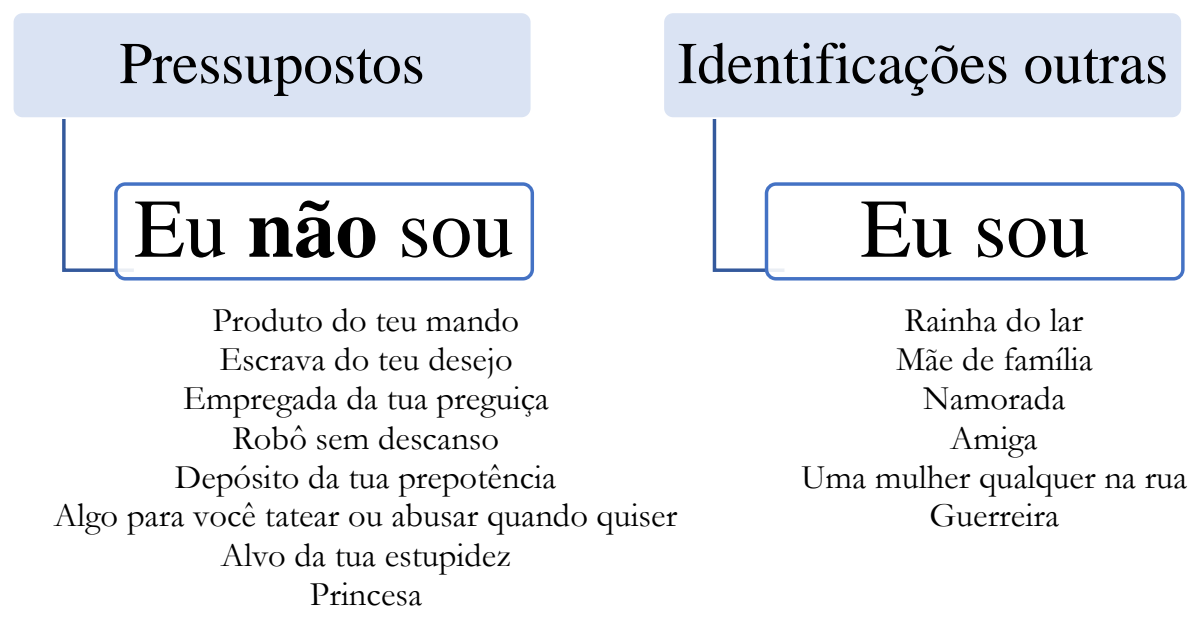

Fonte: elaboração própria.

Os agenciamentos identitários e políticos são indiciados por meio da ruptura com os discursos cristalizados e sustentados no imaginário coletivo, e da reivindicação da equidade de gênero e do direito de ser livre. Em relação aos processos reflexivos, a apropriação dos textos de Sobral por meio da paráfrase criativa e da retórica combativa à imposição da cultura sexista mostram que as propriedades emergentes da reflexividade (discernimento, deliberação e dedicação) foram acionadas e intensificadas por sua experiência com as práticas de leitura de textos protagonistas e com a escrita autoral, culminando com momentos de reelaboração reflexiva.

Considerando funções sociais e objetivos, o gênero mobilizado por Vanessa se caracteriza pela hibridização, pois mescla traços de denúncia, manifesto e testemunho de vida, que traz uma narrativa contra-hegemônica sobre as relações sociais de gênero, baseadas na equidade. $O$ tom contestatório se intensifica e acompanha o ritmo da progressão textual. Como efeito das opressões sistemáticas, não havendo escuta sensível, a resistência assume forma de grito frente ao desafio diário de ser mulher: não vou "abaixar a cabeça pra injustiça" "nem calar minha voz"; "vou bater de frente, pra fazer diferente".

Para finalizar, homenageia a própria mãe, representada como professora da "escola de guerreira", e agradece aos ensinamentos. Por meio da metáfora do espelho, Vanessa se reconhece na história de luta da mãe, vendo-a como exemplo a ser seguido e plasmando a formação da sua identidade pessoal na identidade pessoal da mãe (carrego tua luta no peito, tua bistória em meu ser), o que lhe dá força para resistir e reexistir e se representar com papel ativo. Ao reconhecer suas origens, sagrando o ventre de onde veio, Vanessa honra a própria existência, a trajetória individual e a experiência ética.

O diálogo intertextual com os poemas da autora Cristiane Sobral, por meio da dimensão semântica, do estilo e da perspectiva discursiva, evidencia processos reflexivos e agentivos de afirmação da consciência política e identitária, observada por diferentes estratégias e marcadores linguísticos. Ainda que a estudante possa ter história de formação particular que a permita ter discernimento sobre as desigualdades sociais de gênero, não sendo resultado exclusivo das práticas particulares situadas no PMI e nesse ano letivo específico, mas de uma rede de práticas conectadas historicamente, observa-se que o signo literário transgressivo de Sobral, com sua força agenciadora, estimulou-a a se reconhecer como agente engajada, para recusar-se a ser governada e para contestar 
em escala microssocial, no espaço da sala de aula, os efeitos do sexismo estrutural e subverter estigmas e opressões naturalizados sociodiscursivamente.

\section{CONSIDERAÇÕES FINAIS}

O debate sociopedagógico sobre a construção social de gênero, contemplando diferentes identidades e corpos, constitui uma abordagem necessária quando se almejam relações de gênero mais plurais e democráticas. O debate politicamente engajado, com atenção para a abordagem antissexista e anti-homofóbica, pode promover (micro)resistências criadoras e transgressivas na escola para pensarmos a desconstrução de tais perspectivas e a construção de identificações de gênero mais inclusivas e agentivas.

A descontinuidade em relação à ordem do discurso pedagógico colonial marca a mudança social a partir do contexto escolar. Gêneros, discursos e estilos, como cartazes multimodais e produções literárias autorais e antissexistas, que rompem com o ensino de cariz colonial favorecem agenciamentos epistêmicos que valorizam saberes e experiências globais, locais e dissidentes, novas ordens de discurso e processos de criação. Agenciamentos políticos associam-se à construção da autoria, da desobediência, da transgressão, do protagonismo e do paradigma comunitário. Agenciamentos identitários contemplam as instâncias do pensar, do sentir e do agir e intensificam a agência engajada, o empoderamento, não ficando restrita à dimensão cognitiva do sujeito, pois se abre para compreensões socioculturais e discursivas. Esse processo reflexivo só é viabilizado de fato quando a ordem do discurso pedagógico colonial se altera e produz novas verdades, reconfigurando a rotina escolar.

Por fim, cabe destacar que é imprescindível que o debate sociopedagógico sobre relações de gênero se presentifique cada vez mais no cotidiano da sala de aula, com experiências significativas que envolvam o pensar, o sentir e o agir, de modo que as ressonâncias das práticas discursivo-identitárias, como as do PMI, não estimulem somente o discernimento. É importante que o discernimento se encaminhe para a agência engajada, de modo que a lógica comunitária do bem viver se concretize nas relações sociais dentro da escola e fora dela (HUANACUNI, 2010; WALSH, 2013).

\section{REFERÊNCIAS}

ALBUQUERQUE, Gina. A formação de sujeitos de direitos: o Projeto Mulheres Inspiradoras e o poder transformador da educação. Revista Brasileira de Educação Básica. Ano. 3. Edição Especial. Número 10, Outubro, 2018, p. 1-17.

ARCHER, Margaret. Being human: the problem of agency. United Kingdom: Cambridge University Press, 2004.

BIROLI, Flávia. Gênero e desigualdades: limites da democracia no Brasil. São Paulo: Boitempo, 2018.

BUTLER, Judith. Bodies that matter: on the discursive limits of "sex". New York: Routledge, 1993.

Judith Butler escreve sobre sua teoria de gênero e o ataque sofrido no Brasil, 2017. Disponível em: http://www.ihu.unisinos.br/78-noticias/573806-judith-butler-escreve-sobre-suateoria-de-genero-e-o-ataque-sofrido-no-brasil. Acesso em 19 de agosto de 2020.

CHOULIARAKI, Lilie; FAIRCLOUGH, Norman. Discourse in late modernity: rethinking Critical Discourse Analisy. Edinburgh University Press, 1999.

CURI, Samir. O intertexto escolar: sobre leitura, aula e redação. 2.ed. São Paulo: Cortez, 1998. FAIRCLOUGH, Norman. Discurso e mudança social. Coordenadora de tradução: Izabel Magalhães. 2.ed. Brasília: Universidade de Brasília, 2016 [1992].

Analysing Discourse: textual analisys for social research. London: Routledge, 2003. 
FEDERICI, Silvia. Calibã e a bruxa: mulheres, corpo e acumulação primitiva. Trad. Coletivo Sycorax. São Paulo: Editora Elefante, 2017.

FREIRE, Paulo. Pedagogia do oprimido. Rio de Janeiro: Nova Fronteira, 2012 [1968]. FURLANI, Jimena. Educação sexual na sala de aula: relações de gênero, orientação sexual e igualdade étnico-racial numa proposta de respeito às diferenças. Belo Horizonte: Autêntica Editora, 2011.

GALEFFI, Dante. O anti-intelectualismo nazi-capitalista emergente e o papel do conhecimento científico, filosófico, artístico e místico como resistência crítica e criadora na difusão social do conhecimento. Revista Sul-Sul. Vol. 2, n. 1, 2020. p. 7-24

GARBAGNOLI, Sara. Le vatican contre la dénaturalisation de l'ordre sexuel: structure et enjeux d'un discours institutionnel réactionnaire. Synergies Italie, n. 10, pp. 145-167, 2014.

HOOKS, Bell. Ensinando a transgredir: a educação como prática da liberdade. Tradução de M. Cipolla. São Paulo: Editora WMF Martins Fontes, 2013.

HUANACUNI, Fernando. Buen vivir / Vivir bien: filosofía, políticas, estrategias y experiencias regionales andinas. Lima: Coordinadora Andina de Organizaciones Indígenas (CAOI), 2010.

KILOMBA, Grada. Memórias da plantação: episódios de racismo cotidiano. Tradução de J. Oliveira. Rio de Janeiro: Cobogó, 2019.

KRESS, Gunther; VAN LEEUWEN, Theo. Reading images: the grammar of visual design. London: Routledge, 1996.

KUHAR, Roman.; PATERNOTTE, David. Anti-gender campaigns in Europe: mobilizing against equality. London \& New York: Rowman \& Littlefield International, 2017.

LARROSA, Jorge. La experiencia de la lectura. Petrópolis: Vozes, 2004.

MAGALHÂES, Izabel. Protagonismo da linguagem: textos como agentes. Revista Brasileira de Linguística Aplicada, v. 17, n. 4, p. 575-598, 2017.

MALEWSKI, Erik; JARAMILLO, Nathalia. Epistemologies of ignorance in Education. Charlotte, IAP, 2011.

MCLAREN, Peter. Professores devem assumir o papel de "novos agentes da esperança". In: A página da Educação. Ano 17, 180, julho de 2008. Disponível em: https: / $/$ www.apagina.pt ?aba $=7 \& c a t=180 \& d o c=12700 \& m i d=2$. Acesso em: 12 jan. 2019.

MELLO, Luiz. et al. Para além de um kit anti-homofobia: políticas públicas de educação para a população LGBT no Brasil. Bagoas: Revista de Estudos Gays, v. 7, p. 99-122, 2012

MEZA-LOPEHANDÍA, Matías. Negacionismo y libertad de expression. Biblioteca del Congreso Nacional de Chile. Asesoría técnica parlamentaria. Diciembre, 2018.

NEHER, Clarissa. O negacionismo histórico como arma política. Made for minds, 2019. Disponível em: https://www.dw.com/pt-br/o-negacionismo-hist $\%$ C3\%B3rico-como-armapol\%C3\%ADtica/a-48060402.

PEDRO, Emília. (Org.). Análise Crítica do Discurso: uma perspectiva sociopolítica e funcional. Lisboa: Editorial Caminho, 1997.

QUEIROZ, Atauan Soares de. Educação crítica decolonial e agenciamentos: um estudo etnográfico-discursivo sobre o Programa Mulheres Inspiradoras. Tese (Doutorado). Instituto de Letras, Universidade de Brasília, 2020. 293 f.

Produção escrita na escola: nos caminhos da autoria. Dissertação (Mestrado). Programa de Pós-Graduação em Educação da Faculdade de Educação da Universidade Federal da Bahia, Salvador, 2015. 289f

RAMALHO, Viviane; RESENDE, Viviane. Análise de Discurso Crítica. 2.ed. São Paulo: Contexto, 2011.

ROCHA, João. O verbo dominante nos vídeos dos intelectuais bolsonaristas é eliminar. E o substantivo é limpeza. In: DINIZ, A. Entrevista. Disponível em: 
https://www.jornalopcao.com.br/entrevistas/o-verbo-dominante-nos-videos-dos-intelectuaisbolsonaristas-e-eliminar-e-o-substantivo-e-limpeza-239580/. Acesso em 27 de abril de 2020. SCHOLARS AT RISK. Free to think 2019: report of scholars at risk academic freedom monitoring project. Disponível em: https://www.scholarsatrisk.org/wpcontent/uploads/2019/11/Scholars-at-Risk Acesso em: 09 jan. 2020.

SOBRAL, Cristiane. Não vou mais lavar os pratos. 3.ed. Brasília: Editora Garcia, 2016.

SULLIVAN, Shannon; TUANA, Nancy. Race and epistemologies of ignorance. Albany: State University of New York Press, 2007.

THOMPSON, John. Ideologia e cultura moderna: teoria social crítica na era dos meios de comunicação de massa. 6.ed. Tradução de Carmen Grisci. Petrópolis: Vozes, 2002.

WALSH, Catherine (Ed.). Pedagogías decoloniales: prácticas insurgentes de resistir, (re)existir y (re)vivir. Tomo I. Quito, Ecuador: Ediciones Abya-Yala, 2013.

Submetido em 17/11/2020

Aceito em 20/03/2021 